\title{
Changes and significance of inflammatory cytokines in a rat model of cervical spondylosis
}

\author{
JIANJIAN YIN*, YONGJING HUANG ${ }^{*}$, GONGMING GAO, LUMING NONG, NANWEI XU and DONG ZHOU \\ Department of Orthopedics, Changzhou Second People's Hospital Affiliated to Nanjing Medical University, \\ Changzhou, Jiangsu 213003, P.R. China
}

Received June 21, 2016; Accepted April 10, 2017

DOI: $10.3892 /$ etm.2017.5418

\begin{abstract}
The aim of the present study was to dynamically observe and discuss the significance of inflammatory cytokines in cervical degenerative disease induced by unbalanced dynamic and static forces in rats. A total of 60 Sprague Dawley rats were randomized into test $(n=45)$ and control $(n=15)$ groups, which were randomly subdivided into three groups corresponding to assessment at one, three and six months post-operation. The test group included 10, 15 and 20 rats at the corresponding post-operative stage and the control group had five rats at each time-point. By excising cervicodorsal muscles and ligaments, an unbalanced dynamic and static rat model was established in the test group. At one, three and six-months post-operation, venous serum of test and control group rats was collected and inflammatory cytokines in the serum of all rats were quantitatively determined by ELISA. The results revealed that compared with the control group, the interleukin (IL)-1 $\beta$, IL-10 and tumor necrosis factor- $\alpha$ levels in the test group were significantly increased at one and three months $(\mathrm{P}<0.05,<0.01$ or $<0.001)$, and that IL-12 was significantly increased at three months $(\mathrm{P}<0.05)$. However, transforming growth factor- $\beta 1$ increased at one month but was significantly decreased at three months $(\mathrm{P}<0.01)$. IL-6 did not change significantly throughout the observation period $(\mathrm{P}>0.05)$. In conclusion, cervical vertebral stability may be accompanied with changes of inflammatory cytokines.
\end{abstract}

Correspondence to: Dr Luming Nong, Department of Orthopedics, Changzhou Second People's Hospital Affiliated to Nanjing Medical University, 29 Xinglong Xiang, Zhonglou, Changzhou, Jiangsu 213003, P.R. China

E-mail: 1971487735@qq.com

*Contributed equally

Key words: experimental rat model, dynamic and static forces non-equilibrium, cervical vertebrae degeneration, serum, IL-1 $\beta$, IL-6, IL-10, IL-12, TNF- $\alpha$, TGF- $\beta 1$, ELISA

\section{Introduction}

With long time of work and study, cervical spondylosis is becoming a common disease in modern society. However, the specific pathogenesis has remained to be fully clarified and may result from multiple factors. Cervical instability is considered the main etiological basis of cervical spondylosis. It has been confirmed that destroying the stability of dynamic and static forces of rats may promote cervical disc degeneration (1), which is in line with a previous study by our group (unpublished data). At the same time, the mechanisms associated with changes of inflammatory cytokines in disc degeneration have remained elusive. Mern et al (2) linked vertebral disc degeneration with intradiscal cytokine imbalance, which leads to decreased disc cell density. Wuertz and Haglund (3) suggested that the presence of interleukin (IL)-1 $\beta$, IL-6 and tumor necrosis factor (TNF)- $\alpha$ exacerbates disc degeneration. Shamji et al (4) and Akyol et al (5) reported that disc samples of patients with cervical spondylosis contained higher levels of IL-2, IL-4, IL-10, IL-12 and IL-17 compared with those in healthy control subjects. However, earlier studies have mainly focused on IL-1 $\beta$ and TNF- $\alpha$, which are considered the first inflammatory cytokines in intervertebral discs $(6,7)$, while more recent studies have assessed IL-6, IL- 8 and other cytokines (8-12). As the majority of cervical spondylosis patients are administered drugs, physiotherapy and other conservative treatments, this may interfere with the detection of cytokines to a certain extent. Furthermore, previous studies have used post-operative human cervical nucleus pulposus as samples, while domestic and international studies assessing inflammatory cytokines in the serum appear to be lacking. Finally, the nucleus pulposus is easily contaminated with blood and tissue fluid, which may affect the outcome during the sampling. Therefore, the present study used a rat model of cervical spondylosis by disturbing the cervical equilibrium of dynamic and static forces in order to induce cervical degeneration (13). By detecting the levels of IL-1 $\beta$, IL-6, IL-10, IL-12, transforming growth factor (TGF)- $\beta$ and TNF- $\alpha$ in the serum of experimental and control rats, the association between changes of inflammatory cytokines and cervical degeneration were investigated. The present study provided an experimental basis and reference for clinical prevention and treatment of cervical spondylosis. 


\section{Materials and methods}

Animals. A total of 60 adult and healthy male Sprague Dawley (SD) rats (age, 6 weeks; weight, 220-250 g; Shanghai Laboratory Animal Center, Shanghai, China) were randomized into test $(n=45)$ and control $(n=15)$ groups, which were subdivided into one-, three- and six months post-operation groups. The test group included 10, 15, 20 rats at the corresponding post-operative stages and the control group contained five rats at each time-point. The present study was performed in strict accordance with the recommendations in the Guide for the Care and Use of Laboratory Animals of the National Institutes of Health. The animal protocol was reviewed and approved by the Institutional Animal Care and Use Committee (IACUC) of Nanjing Medical University (Nanjing, China).

Model establishment. Rats in the test group that had been solid-food fasted for $12 \mathrm{~h}$ prior to surgery were anesthetized by intraperitoneal injection with $10 \%$ chloral hydrate $(300 \mathrm{mg} / \mathrm{kg}$; Sinopharm Chemical Reagent Co., Ltd., Shanghai, China) and fixed on the operating table in the prone position with a $50-\mathrm{ml}$ falcon tube under the neck. Subsequent to shaving the nape of the neck and disinfection, a $2-2.5 \mathrm{~cm}$ longitudinal incision was made at the midline to perforate the skin and subcutaneous tissue. Every muscle layer was fully separated. Superficial muscles, platysma muscle, trapezius and rhomboideus, and deeper muscles, splenius cervicis muscle, longissimus capitis et atlantis, longissimus cervicis, hiocostalis cervicis and semispinalis capitis were transected successively, and $1.5 \mathrm{~cm}$ of those muscles were resected to avoid coalescence. At last, supraspinous ligament and interspinous ligaments from $\mathrm{C} 2$ to $\mathrm{C} 7$ were cut off prior to suturing skin layers successively, without removing the sutures, which came off naturally. The preparation prior to surgery and anesthesia for rats in the pseudo-surgery (control) group was the same as that in the test group. The skin incision of rats in the control group was sutured without resecting or cutting any muscle or ligament. Each rat was fed a standard diet and had access to food and water ad libitum in individual cages under normal conditions at $23-25^{\circ} \mathrm{C}$ with a relative humidity of $40-70 \%$ and a $12-\mathrm{h}$ light/dark cycle with intramuscular injection of 50,000 units penicillin sodium to prevent infection following surgery.

Index assessment. At one, three or six months post-surgery, the serum of rats in the control and experimental groups was obtained following intraperitoneal anesthesia with $10 \%$ chloral hydrate from the intraperitoneal venous blood by centrifugation at $630 \mathrm{x} \mathrm{g}$ for $15 \mathrm{~min}$ at $4^{\circ} \mathrm{C}$, and preserved at $-80^{\circ} \mathrm{C}$ after. Serum IL-1 $\beta$, IL-6, IL-10, TGF- $\beta 1$ and TNF- $\alpha$ levels were measured using a standard quantitative sandwich ELISA (MultiSciences Biotech Co., Ltd., Hangzhou, Zhejiang, China), and serum IL-12 levels were measured using a standard quantitative sandwich ELISA (Nanjing Jiancheng Bioengineering Institute, Nanjing China) with a $1.42 \mathrm{pg} / \mathrm{ml}$ (IL-1ß), $2.57 \mathrm{pg} / \mathrm{ml}$ (IL-6), 0.48 pg/ml (IL-10), 3 pg/ml (IL-12), $7.14 \mathrm{pg} / \mathrm{ml}$ (TNF- $\alpha), 31.25 \mathrm{pg} / \mathrm{ml}$ (TGF- $\beta 1)$ detection limit of sensitivity. The minimum detectable dose was determined by adding two standard deviations to the mean optical density value of ten zero standard replicates and calculating the corresponding concentration. Serum samples were diluted
1:5 or 1:10 in PBS. Concentrations were reported as $\mathrm{pg} / \mathrm{ml}$. All analyses and calibrations were performed in duplicate. Optical densities were determined using an absorbance microplate reader (Elx808 ${ }^{\mathrm{Tm}}$; Bio-Tek Instruments, Winooski, VT, USA) at $450 \mathrm{~nm}$. GraphPad Prism Data Analysis software 6 (GraphPad Software, Inc., La Jolla, CA, USA). was used to analyze all materials and depict the standard curve.

Statistical analysis. Values are expressed as the mean \pm standard deviation. Statistical analyses were performed with GraphPad Prism 6 (GraphPad Software, Inc.). F-test was used to assess the equality of variances. If variances were equal, a Students t-test was employed to compare mean values among groups. The Rank-sum test was performed if data were not normally distributed or variances were not equal. $\mathrm{P}<0.05$ was determined to indicate statistically significant difference.

\section{Results}

General observation. Forty-five SD rats in the test group underwent surgery without any perioperative mortality and were characterized by head bobbing, twisting and shaking that disappeared within approximately one week. At seven days after surgery, five rats had died (Table I) and were dissected, revealing cervical infection and intestinal tympaniteses. No further mortality was observed at one, three and six months post-operation.

Changes in inflammatory cytokine levels. The serum inflammatory cytokine levels in the two groups at different time-points are shown in Table II. The content of IL-1 $\beta$ in the control group at one, three and six months post-operation was $97.76 \pm 13.33,112.69 \pm 33.35$ and $99.78 \pm 13.44 \mathrm{pg} / \mathrm{ml}$, respectively, while that in the experimental group was $266.69 \pm 85.33$, $211.22 \pm 49.23$ and $143.71 \pm 38.58 \mathrm{pg} / \mathrm{ml}$, respectively. Compared with that in the control group, the serum IL-1 $\beta$ content in the experimental group was significantly increased at one and three months $(\mathrm{P}<0.05$; Fig. 1$)$.

The content of IL- 6 in the control group at one, three and six months post-operation was $261.05 \pm 14.69,257.84 \pm 7.87$ and $254.80 \pm 21.13 \mathrm{pg} / \mathrm{ml}$, respectively, while that in the experimental group was $269.99 \pm 13.87,262.61 \pm 12.20$ and $266.40 \pm 16.59 \mathrm{pg} / \mathrm{ml}$, respectively. Compared with that in the control group, the IL- 6 content in the experimental group showed no significant change at any of the time-points (Fig. 2).

The content of IL-10 in the control group at one, three and six months post-operation was $59.81 \pm 3.68,64.60 \pm 0.96$ and $59.82 \pm 13.11 \mathrm{pg} / \mathrm{ml}$, respectively, while that in the experimental group was $94.65 \pm 9.37,111.73 \pm 10.42$ and $69.93 \pm 9.69 \mathrm{pg} / \mathrm{ml}$, respectively. Compared with those in the control group, the serum levels of IL-10 in the experimental group were significantly increased at one and three months $(\mathrm{P}<0.001$; Fig. 3).

The content of IL-12 in the control group at one, three and six months post-surgery was $315.74 \pm 34.32,268.21 \pm 77.31$ and $322.83 \pm 34.77 \mathrm{pg} / \mathrm{ml}$, respectively, while that in the experimental group was $333.73 \pm 37.25,375.56 \pm 40.70$ and $339.37 \pm 20.56 \mathrm{pg} / \mathrm{ml}$, respectively. Compared with the control group, the serum levels of IL-12 in the experimental group were significantly increased at three month $(\mathrm{P}<0.05$; Fig. 4). 
Table I. Survival rate of animals in the present study.

\begin{tabular}{lccccccc}
\hline \multirow{3}{*}{$\begin{array}{l}\text { Time } \\
\text { (months) }\end{array}$} & \multicolumn{3}{c}{ Control group } & & \multicolumn{3}{c}{ Experimental group } \\
\cline { 2 - 3 } & Total (n) & Survived, n (\%) & Died (n) & & Total (n) & Survived, n (\%) & Died (n) \\
\hline 1 & 5 & $5(100)$ & 0 & & 10 & $9(90)$ & 1 \\
3 & 5 & $5(100)$ & 0 & & 15 & $13(87)$ & 2 \\
6 & 5 & $5(100)$ & 0 & & 20 & $18(90)$ & 2 \\
\hline
\end{tabular}

Table II. Serum inflammatory cytokine content in rats ( $\mathrm{pg} / \mathrm{ml})$.

\begin{tabular}{|c|c|c|c|}
\hline \multirow[b]{2}{*}{ Cytokine } & \multirow[b]{2}{*}{$\begin{array}{c}\text { Time } \\
\text { (months) }\end{array}$} & \multicolumn{2}{|c|}{ Group } \\
\hline & & Control group & $\begin{array}{l}\text { Experimental } \\
\text { group }\end{array}$ \\
\hline \multirow[t]{3}{*}{ IL-1 $\beta$} & 1 & $97.76 \pm 13.33$ & $266.69 \pm 85.33^{\mathrm{a}}$ \\
\hline & 3 & $112.69 \pm 33.35$ & $211.22 \pm 49.23^{\mathrm{a}}$ \\
\hline & 6 & $99.78 \pm 13.44$ & $143.71 \pm 38.58$ \\
\hline \multirow[t]{3}{*}{ IL-6 } & 1 & $261.05 \pm 14.69$ & $269.99 \pm 13.87$ \\
\hline & 3 & $257.84 \pm 7.87$ & $262.61 \pm 12.20$ \\
\hline & 6 & $254.80 \pm 21.13$ & $266.40 \pm 16.59$ \\
\hline \multirow[t]{3}{*}{ IL-10 } & 1 & $59.81 \pm 3.68$ & $94.65 \pm 9.37^{\mathrm{b}}$ \\
\hline & 3 & $64.60 \pm 0.96$ & $111.73 \pm 10.42^{\mathrm{b}}$ \\
\hline & 6 & $59.82 \pm 13.11$ & $69.93 \pm 9.69$ \\
\hline \multirow[t]{3}{*}{ IL-12 } & 1 & $315.74 \pm 34.32$ & $333.73 \pm 37.25$ \\
\hline & 3 & $268.21 \pm 77.31$ & $375.56 \pm 40.70^{\mathrm{a}}$ \\
\hline & 6 & $322.83 \pm 34.77$ & $339.37 \pm 20.56$ \\
\hline \multirow[t]{3}{*}{ TNF- $\alpha$} & 1 & $79.55 \pm 7.64$ & $147.15 \pm 26.12^{\mathrm{c}}$ \\
\hline & 3 & $74.54 \pm 2.23$ & $144.39 \pm 29.45^{\mathrm{c}}$ \\
\hline & 6 & $79.60 \pm 11.76$ & $101.59 \pm 16.19$ \\
\hline \multirow[t]{3}{*}{ TGF- $\beta 1$} & 1 & $4,214.21 \pm 258.59$ & $4,789.72 \pm 633.27$ \\
\hline & 3 & $4,894.47 \pm 327.32$ & $4,044.79 \pm 361.26^{\circ}$ \\
\hline & 6 & $3,608.41 \pm 387.11$ & $3,333.52 \pm 251.41$ \\
\hline
\end{tabular}

Values are expressed as the mean \pm standard deviation. ${ }^{\mathrm{a}} \mathrm{P}<0.05$, ${ }^{\mathrm{b}} \mathrm{P}<0.001,{ }^{\mathrm{c}} \mathrm{P}<0.01$ vs. control group. CG, control group; EG, experimental group; IL, interleukin; TNF, tumor necrosis factor; TGF, transforming growth factor.

The content of TNF- $\alpha$ in the control group at one, three and six months post-operation was $79.55 \pm 7.64,74.54 \pm 2.23$ and $79.60 \pm 11.76 \mathrm{pg} / \mathrm{ml}$, respectively, while that in the experimental group was $147.15 \pm 26.12,144.39 \pm 29.45$ and $101.59 \pm 16.19 \mathrm{pg} / \mathrm{ml}$, respectively. Compared with those in the control group, the serum levels of TNF- $\alpha$ in the experimental group were significantly increased at one and three months $(\mathrm{P}<0.01 ;$ Fig. 5$)$.

The content of TGF- $\beta 1$ in the control group at one, three and six months post-operation were 4,214.21 \pm 258.59 , $4,894.47 \pm 327.32$ and $3,608.41 \pm 387.11 \mathrm{pg} / \mathrm{ml}$, respectively, while those in the experimental group were $4,789.72 \pm 633.27$, $4,044.79 \pm 361.26$ and $3,333.52 \pm 251.41 \mathrm{pg} / \mathrm{ml}$, respectively. Compared with the control group, there was an increasing trend in TGF- $\beta 1$ content at one month, which may have been

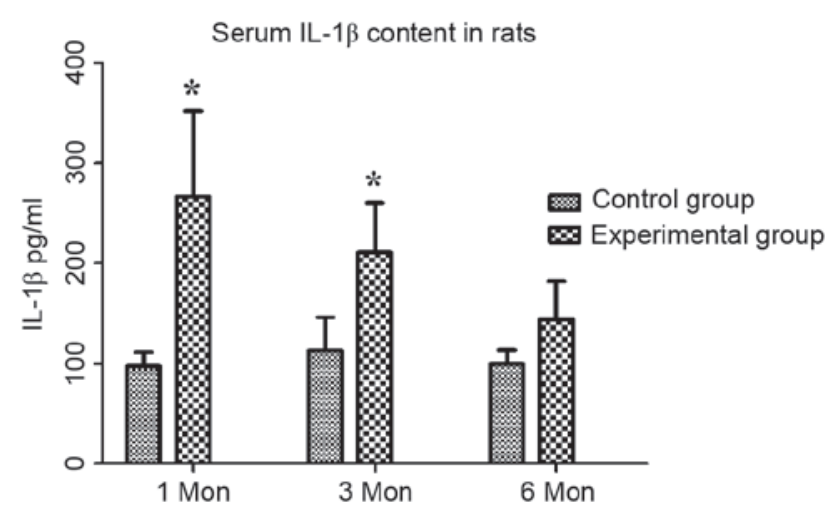

Figure 1. Serum IL-1 $\beta$ content in rats (pg/ml). Compared with those in the control group, the serum IL- $1 \beta$ content in the experimental group as significantly increased at one and three months. ${ }^{*} \mathrm{P}<0.05$ vs. control. Values are expressed as the mean \pm standard deviation. IL, interleukin; Mon, months.

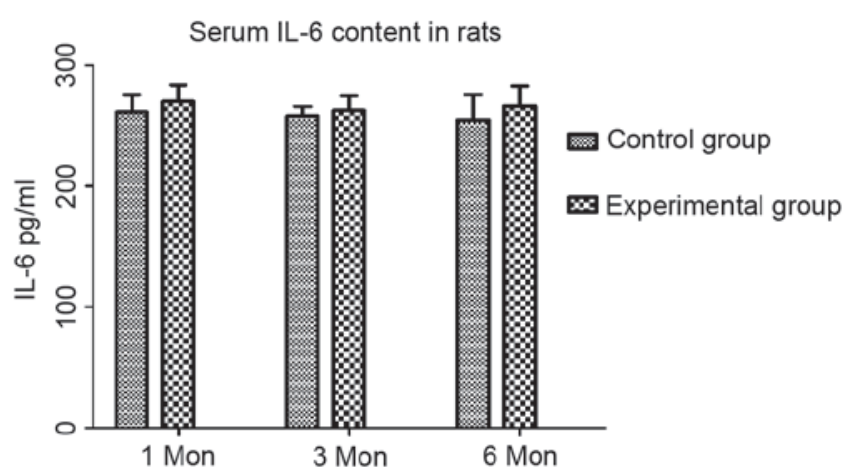

Figure 2. Serum IL-6 content in rats $(\mathrm{pg} / \mathrm{ml})$. Compared with those in the control group, the IL- 6 content in the experimental group was not significantly changed at any of the time-points. Values are expressed as the mean \pm standard deviation. IL, interleukin; Mon, months.

a compensatory increase, followed by a significant decrease at three months $(\mathrm{P}<0.01$; Fig. 6).

Following investigation of post-operative healing in the two groups it was demonstrated that part of the cervical back muscle in the experimental group healed and exhibited scarring over time, especially at 6 months post-surgery (Fig. 7). In the control group, the incision healed well and the cervical back muscle was well arranged under the subcutaneous tissue.

\section{Discussion}

The present study successfully established a rat model of cervical spondylosis by creating a non-equilibrium of dynamic 


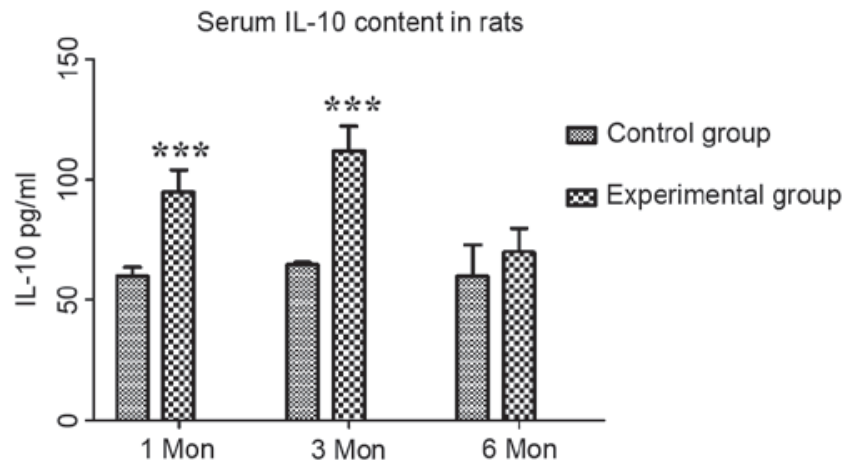

Figure 3. Serum IL-10 content in rats $(\mathrm{pg} / \mathrm{ml})$. Compared with those in the control group, the serum levels of IL-10 in the experimental group were significantly increased at one and three months. ${ }^{* * *} \mathrm{P}<0.001$ vs. control. Values are expressed as the mean \pm standard deviation. IL, interleukin; Mon, months.

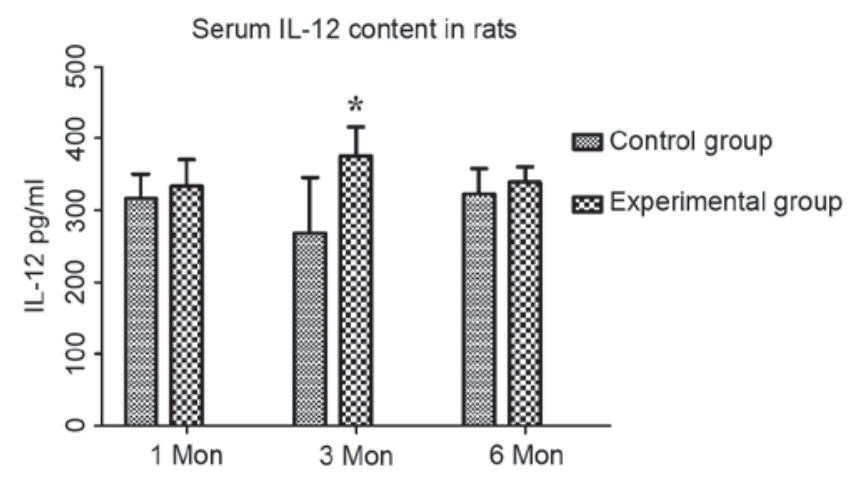

Figure 4. Serum IL-12 content in rats (pg/ml). Compared with those in the control group, the serum levels of IL-12 in the experimental group were significantly increased at three months. ${ }^{*} \mathrm{P}<0.05$ vs. control. Values are expressed as the mean \pm standard deviation. IL, interleukin; Mon, months.

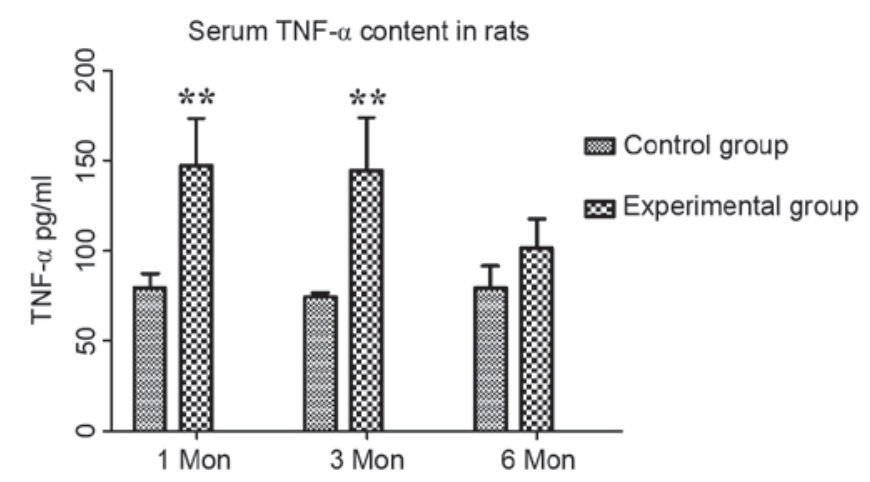

Figure 5. Serum TNF- $\alpha$ content in rats (pg/ml). Compared with those in the control group, the serum levels of TNF- $\alpha$ in the experimental group were significantly increased in at one and three months. ${ }^{* *} \mathrm{P}<0.01 \mathrm{vs}$. control. Values are expressed as the mean \pm standard deviation. TNF, tumor necrosis factor; Mon, months.

and static forces. X-ray analysis (unpublished data) of the cervical spine of experimental group rats revealed degenerative manifestations, including disappearance of the cervical physiological curvature, reduction of the intervertebral foramen in size and narrowing of the disc space. The animal model of cervical degeneration provided a reliable sample for

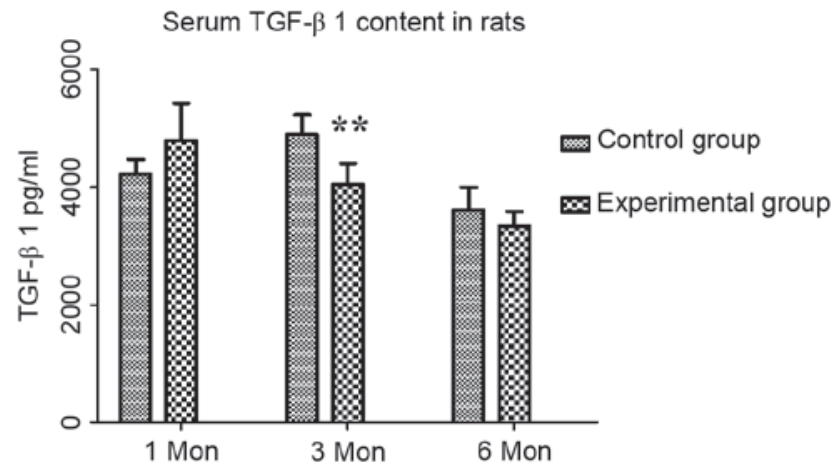

Figure 6. Serum TGF- $\beta 1$ content in rats $(\mathrm{pg} / \mathrm{ml})$. Compared with that in the control group, there was an increasing trend in the TGF- $\beta 1$ content at one month, which may have been a compensatory increase, and was significantly decreased at three months. ${ }^{* *} \mathrm{P}<0.01$ vs. control. Values are expressed as the mean \pm standard deviation. TGF, transforming growth factor; Mon, months.
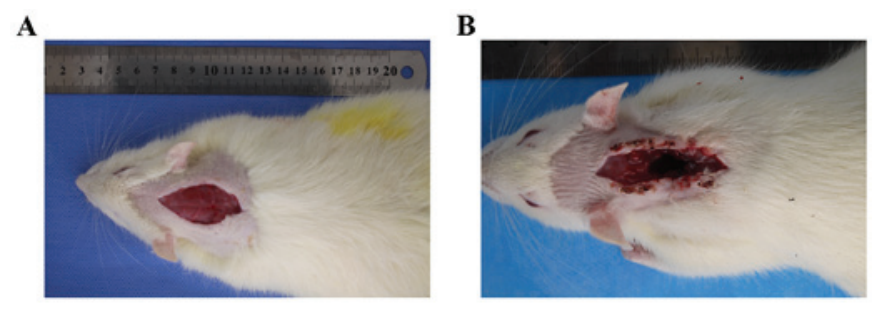

C

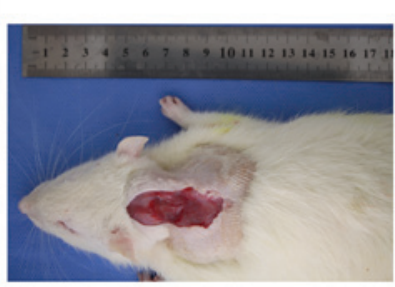

D

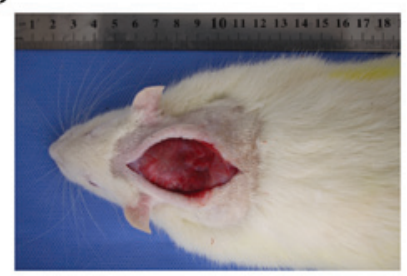

Figure 7. Rats in the two groups were anesthetized at each time-point post-operation and an incision was made to observe the healing condition. (A) Control group; (B) 1, (C) 3 and (D) 6 months post-surgery in the experimental group. Part of the cervical back muscle in the experimental group healed and scarred over time.

future studies on the association between serum inflammatory cytokines and cervical degeneration.

Cytokines are glycoproteins produced by a variety of cells and are secreted into the extracellular space to participate in the immune response and inflammatory regulation. As a research hot spot, IL-1 $\beta$ is thought to be the most important cytokine, with a strong pro-inflammatory activity by stimulating the production of multiple pro-inflammatory mediators such as cytokines, chemokines and matrix metalloproteinases (14-16). In addition, IL-1 $\beta$ promotes oxidative stress and accelerates the degradation of extracellular matrix by inducing cell senescence apoptosis, thereby accelerating disc degeneration (17). In the present study, the serum IL-1 $\beta$ content was elevated in parallel with the progression of cervical degeneration at one and three months, suggesting that IL-1 $\beta$ is an important inflammatory mediator with a pivotal role in cervical degeneration. Degeneration of the cervical vertebrae accompanied by a high level of local IL- $1 \beta$ and IL- $1 \beta$ mediated a strong inflammatory response, and local inflammation accelerates the oxidation of intervertebral disc cells and degradation of 
extracellular matrix, which facilitates disc degeneration. In another study by Smith et al (18), co-treatment with IL-1 $\beta$ and IL-1 receptor antagonist almost completely reversed degenerative changes of bovine nucleus pulposus cells induced by IL-1 $\beta$. This conclusion inspired us to treat cervical disc degeneration by eliminating local inflammatory factors and cytokines to restore intra-disc homeostasis, e.g. by intra-disc injection of cytokine receptor antagonists. Sainoh et al (19) demonstrated that intradiscal tocilizumab injection exerted a short-term analgesic effect in patients with discogenic low back pain, however further research is required to determine the long-term effects.

A previous study suggested that the level of TNF- $\alpha$ is closely associated with cervical pain of patients with cervical spondylosis. TNF- $\alpha$ facilitates neurovascular ingrowth via increasing the production of nerve growth factor and vascular endothelial growth factor. It also facilitates matrix degradation and upregulates substance $P$, suggesting it may sensitize nerves to painful responses or facilitate structural disruption $(20,21)$. Lai et al (22) confirmed that compared with the changed cervical structure or partial neurovascular hyperplasia, the pain caused by cervical spondylosis was more closely linked with local inflammation. When comparing nucleus pulposus material from disk herniation vs. painful degenerative disk disease, higher levels of TNF- $\alpha$ were detected in the painful degenerative disk disease group $(23,24)$. In the present study, elevated serum TNF- $\alpha$ content and cervical degeneration showed a positive association at the first and third months, suggesting that the pain caused by cervical degeneration was chronically sustained and intensified over the first three months, accompanied by degeneration of the cervical vertebrae.

IL-12 is mainly produced by dendritic cells and macrophages, with a wide range of immune and pro-inflammatory effects by promoting the secretion of interferon $-\gamma$ and has an enhanced role in other pro-inflammatory reactions $(25,26)$. T-lymphocytes are major inflammatory cells in cervical disc tissue, its cell subsets, particularly the imbalance of T-helper type 1 vs. type 2 cell subsets and cytokines may be associated with cervical degeneration, and IL-12 has an important role in T-cell mediated autoimmune diseases (27). Akyol et al (28) found that the expression of IL-12 significantly increased in cervical disc tissue of cervical spondylosis patients compared with that in the control group. The present study assessed serum samples and found that the amount of IL-12 in the experimental group was significantly increased at 3 months post-operation compared with that in the control group. However, the increasing trend of IL-12 in serum samples was not as remarkable as that in disc samples. It is therefore speculated that IL-12 is mainly involved in the immune response in disc tissue but less in serum.

IL-10 is a homodimeric anti-inflammatory $36-\mathrm{kDa}$ cytokine produced by monocytes and lymphocytes. Anti-inflammatory IL-10 is probably increased in intervertebral disk disease as a result of the tight coupling of the pro-inflammatory arm of the local disk disease process with an anti-inflammatory regulatory arm of the response, which is necessary to prevent excessive stimulation and tissue destruction (29). A previous study found more IL-10-positive cells in the degenerated discs than in the control discs (30). Similarly, the present study revealed that the expression of IL-10 was gradually increased, which is consistent with the above conclusions. IL-10 is known to have a major role in the anti-inflammatory response and is raised as a feedback effect. Li et al (31) observed that either TGF- $\beta$ or IL-10 alone suppressed the expression of inflammatory cytokines. Furthermore, their combined use produced a higher level of inhibition of TNF- $\alpha$ and IL-1 $\beta$ than either TGF- $\beta$ or IL-10 alone. It was therefore speculated that IL-10 may be involved in an anti-degeneration mechanism in the cervical degeneration process.

It is similar to the cytokine IL-10, Maltman et al (32) found that TGF- $\beta$ guides abnormal bone remodeling, and has a vital role in maintaining articular cartilage and subchondral bone homeostasis. TGF- $\beta$ has been reported to increase proteoglycan production to adjust the proliferation of type II collagen intervertebral disk cells and reduce matrix degradation to thereby regulate the metabolism of intervertebral disc cells $(33,34)$. While certain studies found that proteoglycan production in nucleus pulposus cells was increased through gene therapy with TGF- $\beta$, it is inferred that TGF- $\beta$ is a protective cytokine in the intervertebral disc (35-37). In the present study, an increasing trend of TGF- $\beta 1$ at 1 month post-operation was identified, while it had significantly decreased at 3 months. This may be the body's protective response to cervical degeneration. As TGF- $\beta$ decreased earlier than other cytokines, it may be speculated that the early stage of cervical degeneration may be accompanied with the increase of TGF- $\beta 1$. TGF- $\beta 1$ may then activate the body's anti-cervical degeneration mechanism by increasing the production and reducing the degradation of proteoglycan matrix, guiding bone and cartilage remodeling to restore the stability of the local cervical spine. The specific mechanisms still require to be further investigated.

Kishimoto et al (38) proposed that IL-6 is a multifunctional cytokine involved in cell proliferation and differentiation, maintaining immune homeostasis, macrophage function and other key functions. It has been confirmed that IL- 6 can be used as a pro-inflammatory cytokine, which may cause secondary injury $(39,40)$. Sainoh et al (41) achieved a pain reduction by intra-disc injection of IL-6 inhibitor. Miyagi et al (42) found that the expression of IL- 6 in a rat model of intervertebral disc injury increased steadily from the first to the fourth day compared with that in the control group. Sainoh et al (41) found that IL-6 and IL-6 receptor levels reached a maximum on the first day post-disc injury and then gradually decreased in injured intervertebral discs over time compared to those in the disks of non-injured mice. Conversely, in the present study, no significant changes in the serum levels of IL-6 were found in the test and control groups at any time-point. The possible reasons may be as follows: First, the sample detection in the above studies was usually within a few days after model establishment, but was at least one month in the present study. Differences in species between studies may be another factor affecting the results of the experiments. Finally, the present study assessed serum samples, while the above studies assessed cytokine levels in the intervertebral disc, which may have influenced the outcome. Xiang et al (43) reported that inflammatory cytokines in degenerative disc tissue were significantly higher than those in serum, which confirms this conjecture. 
Of note, the present study found that in the experimental group, the levels of IL-1 $\beta$, IL-6, IL-10, IL-12, TGF- $\beta$ and TNF- $\alpha$ at six months had obviously decreased compared with those at one and three months. This may be associated with the partial healing of neck muscles and scarring, which may in part lead to the recovery of cervical vertebral stability. The recovery of cervical vertebral stability retards the process of cervical degeneration, resulting in the decrease of inflammatory cytokines. It is therefore inferred that the changes of inflammatory cytokines were associated with cervical vertebral stability, but not with cervical degeneration. The initiating factors of cervical spondylosis therefore remain to be elucidated.

The present study preliminarily assessed the association between serum inflammatory cytokines and cervical degeneration. However, there is a limitation as the addition of another control group, in which comparable muscles in different parts of mice were cut, is required. The changes in cytokines may have been due to muscle ligation rather than spine-associated processes. However, the expression of associated genes and signal transduction pathways in the process of cervical degeneration has remained indeterminate and will be the focus of further study.

\section{Acknowledgements}

The present study was supported by the Project of Invigorating Health Care Through Science, Technology and Education (Jiangsu Provincial Medical Youth Talent), Changzhou City High Level Health Personnel Training Project (grant no. 2016CZBJ029), Changzhou International Scientific and Technological Cooperation Project (grant no. CZ20170021), Jiangsu Postdoctoral Research supported project (grant no. 1701001A).

\section{References}

1. Miyamoto S, Yonenobu K and Ono K. Experimental cervical spondylosis in the mouse. Spine (Phila Pa 1976) 16 (10 Suppl): S495-S500, 1991.

2. Mern DS, Beierfuss A, Thome C and Hegewald AN: Enhancing human nucleus pulposus cells for biological treatment approaches of degenerative intervertebral disc diseases: A systematic review. J Tissue Eng Regenerative Med 8: 925-936, 2014.

3. Wuertz K and Haglund L: Inflammatory mediators in intervertebral disk degeneration and discogenic pain. Global Spine J 3 : $175-184,2013$

4. Shamji MF, Setton LA, Jarvis W, So S, Chen J, Jing L, Bullock R, Isaacs RE, Brown $\mathrm{C}$ and Richardson WJ: Proinflammatory cytokine expression profile in degenerated and herniated human intervertebral disc tissues. Arthritis Rheum 62: 1974-1982, 2010

5. Akyol S, Eraslan BS, Etyemez H, Tanriverdi T and Hanci M: Cataboliccytokine expressions in patients with degenerative disc disease. Turk Neurosurg 20: 492-499, 2010.

6. Le Maitre CL, Freemont AJ and Hoyland JA: The role of interleukin-1 in the pathogenesis of human intervertebral disc degeneration. Arthritis Res Ther 7: R732-R745, 2005.

7. Le Maitre CL, Hoyland JA and Freemont AJ: Catabolic cytokine expression in degenerate and herniated human intervertebral discs: IL-1beta and TNFalpha expression profile. Arthritis Res Ther 9: R77, 2007.

8. Risbud MV and Shapiro IM: Role of cytokines in intervertebral disc degeneration: Pain and disc content. Nat Rev Rheumatol 10 44-56, 2014.

9. Sutovsky J, Benco M, Sutovska M, Kocmalova M, Pappova L, Miklusica J, Frano A and Kurca E: Cytokine and chemokine profile changes in patients with lower segment lumbar degenerative spondylolisthesis. Int J Surg 43: 163-170, 2017.
10. Zhang Y, Zhao Y, Li J, Wang S, Liu Y, Nie L and Cheng L: Interleukin-9 Promotes TNF- $\alpha$ and PGE2 release in human degenerated intervertebral disc tissues. Spine (Phila Pa 1976) 41: 1631-1640, 2016.

11. Schroeder GD, Markova DZ, Koerner JD, Rihn JA, Hilibrand AS, Vaccaro AR, Anderson DG and Kepler CK: Are Modic changes associated with intervertebral disc cytokine profiles? Spine J 17: 129-134, 2017.

12. Kuelling FA, Foley KT, Liu JJ, Liebenberg E, Sin AH, Matsukawa A and Lotz JC: The anabolic effect of plasma-mediated ablation on the intervertebral disc: Stimulation of proteoglycan and interleukin-8 production. Spine J 14: 2479-2487, 2014

13. Wang YJ, Shi Q, Lu WW, Cheung KC, Darowish M, Li TF, Dong YF, Zhou CJ, Zhou Q, Hu ZJ, et al: Cervical intervertebral disc degeneration induced by unbalanced dynamic and static forces: A novel in vivo rat model. Spine (Phila Pa 1976) 31: 1532-1538, 2006.

14. Dinarello CA: Immunological and inflammatory functions of the interleukin-1 family, Annu Rev Immunol 27: 519-550, 2009.

15. Dinarello CA: Interleukin-1 in the pathogenesis and treatment of inflammatory diseases. Blood 117: 3720-3732, 2011.

16. Rosenzweig JM, Lei J and Burd I: Interleukin-1 receptor blockade in perinatal brain injury. Front Pediatr 2: 108, 2014.

17. Yang W, Yu XH, Wang C, He WS, Zhang SJ, Yan YG, Zhang J, Xiang YX and Wang WJ: Interleukin- $1 \beta$ in intervertebral disk degeneration Clinica Chimica Acta 450: 262-272, 2015.

18. Smith LJ, Chiaro JA, Nerurkar NL, Cortes DH, Horava SD, Hebela NM, Mauck RL, Dodge GR and Elliott DM: Nucleus pulposus cells synthesize a functional extracellular matrix and respond to inflammatory cytokine challenge following long-term agarose culture. Eur Cell Mater 22: 291-301, 2011.

19. Sainoh T, Orita S, Miyagi M, Inoue G, Kamoda H, Ishikawa T, Yamauchi K, Suzuki M, Sakuma Y, Kubota G, et al: Single intradiscal administration of the tumor necrosis factor-alpha inhibitor, etanercept, for patients with discogenic low back pain. Pain Med 17: 40-45, 2016.

20. Séguin CA, Pilliar RM, Roughley PJ and Kandel RA: Tumor necrosis factor-alpha modulates matrix production and catabolism in nucleus pulposus tissue. Spine (Phila $\mathrm{Pa} 1976)$ 30: 1940-1948, 2005.

21. Purmessur D, Freemont AJ and Hoyland JA: Expression and regulation of neurotrophins in the nondegenerate and degenerate human intervertebral disc. Arthritis Res Ther 10: R99, 2008.

22. Lai A, Moon A, Purmessur D, Skovrlj B, Laudier DM, Winkelstein BA, Cho SK, Hecht AC and Iatridis JC: Annular puncture with tumor necrosis factor-alpha injection enhances painful behavior with disc degeneration in vivo. Spine J 16: 420-431, 2015.

23. Lee S, Moon CS, Sul D, Lee J, Bae M, Hong Y, Lee M, Choi S, Derby R, Kim BJ, et al: Comparison of growth factor and cytokine expression in patients with degenerated disc disease and herniated nucleus pulposus. Clin Biochem 42: 1504-1511, 2009.

24. Burke JG, Watson RW, McCormack D, Dowling FE, Walsh MG and Fitzpatrick JM: Intervertebral discs which cause low back pain secrete high levels of proinflammatory mediators. J Bone Joint Surg Br 84: 196-201, 2002.

25. Starbeck-Miller GR, Xue HH and Harty JT: IL-12 and type I interferon prolong the division of activated CD8 T cells by maintaining high-affinity IL-2 signaling in vivo, J Exp Med 211: 105-120, 2014.

26. Garcia K, Sun Z, Mattson E, Li L, Smyth K and Xiao Z: IL-12 is required for mTOR regulation of memory CTLs during viral infection. Genes Immun 15: 413-423, 2014.

27. Abdi K and Singh NJ: Singh Making many from few: IL-12p40 as a model for the combinatorial assembly of heterodimeric cytokines. Cytokine 76: 53-57, 2015.

28. Akyol S, Eraslan BS, Etyemez H, Tanriverdi T and Hanci M: Catabolic cytokine expressions in patients with degenerative disc disease. Turk Neurosurg 20: 492-499, 2010.

29. Lin WP, Lin JH, Chen XW, Wu CY, Zhang LQ and Lai JM: Interleukin-10 promoter polymorphisms associated with susceptibility to lumbar disc degeneration in a Chinese cohort. Genetics Mol Res 10: 1719-1727, 2011.

30. Holm S, Mackiewicz Z, Holm AK, Konttinen YT, Kouri VP, Indahl $A$ and Salo J: Pro-inflammatory, pleiotropic, and anti-inflammatory TNF-alpha, IL-6, and IL-10 in experimental porcine intervertebral disk degeneration. Vet Pathol 46: 1292-1300, 2009. 
31. Li W, Liu T, Wu L, Chen C, Jia Z, Bai X and Ruan D: Blocking the function of inflammatory cytokines and mediators by using IL-10 and TGF- $\beta$ : A potential biological immunotherapy for intervertebral disc degeneration in a beagle model. Int $\mathbf{J}$ Mol Sci 15: 17270-17283, 2014.

32. Maltman J, Pragnell IB and Graham GJ: Specificity and reciprocity in the interactions between TGF-beta and macrophage inflammatory protein-1 alpha. J Immunol 156: 1566-1571, 1996.

33. Zhen $\mathrm{G}$ and Cao X: Targeting TGF $\beta$ signaling in subchondra bone and articular cartilage homeostasis. Trends Pharmacol Sci 35: 227-236, 2014.

34. Nishida K, Kang JD, Gilbertson LG, Moon SH, Suh JK, Vogt MT, Robbins PD and Evans CH: Modulation of the biologic activity of the rabbit intervertebral disc by gene therapy: An in vivo study of adenovirus-mediated transfer of the human transforming growth factor beta 1 encoding gene. Spine (Phila Pa 1976) 24: 2419-2425, 1999.

35. Illien-Jünger S, Lu Y, Purmessur D, Mayer JE, Walter BA, Roughley PJ, Qureshi SA, Hecht AC and Iatridis JC: Detrimental effects of discectomy on intervertebral disc biology can be decelerated by growth factor treatment during surgery - a large animal organ culture mode. Spine J 14: 2724-2732, 2014,

36. Cho H, Lee S, Park SH, Huang J, Hasty KA and Kim SJ: Synergistic effect of combined growth factors in porcine intervertebral disc degeneration. Connect Tissue Res 54: 181-186, 2013.
37. Abbott RD, Purmessur D, Monsey RD, Brigstock DR, Laudier DM and Iatridis JC: Degenerative grade affects the responses of human nucleus pulposus cells to link-N, CTGF, and TGF33. J Spinal Disord Tech 26: E86- E94, 2013.

38. Kishimoto T, Akira S, Narazaki $M$ and Taga T: Interleukin-6 family of cytokines and gp130. Blood 86: 1243-1254, 1995.

39. Gruol DL: IL-6 regulation of synaptic function in the CNS. Neuropharmacology 96: 42-54, 2015.

40. Gruol DL, Puro A, Hao C, Blakely P, Janneke E and Vo K: Neuroadaptive changes in cerebellar neurons induced by chronic exposure to IL-6. J Neuroimmunol 239, 28-36, 2011.

41. Sainoh T, Orita S, Miyagi M, Sakuma Y, Yamauchi K, Suzuki M, Kubota G, Oikawa Y, Inage K, Sato J, et al: Interleukin-6 and interleukin-6 receptor expression, localization and involvement in pain-sensing neuron activation in a mouse intervertebral disc injury mode. J Orthop Res 33: 1508-1514, 2015.

42. Miyagi M, Ishikawa T, Orita S, Eguchi Y, Kamoda H, Arai G, Suzuki M, Inoue G, Aoki Y, Toyone T, et al: Disk injury in rats produces persistent increases in pain-related neuropeptides in dorsal root ganglia and spinal cord glia but only transient increases in inflammatory mediators: Pathomechanism of chronic diskogenic low back pain. Spine (PhilaPa 1976) 36: 2260-2266, 2011

43. Xiang YJ, Shen XH, Shen Z, et al: Local inflammatory cytokine changes in degenerative vertebal discs in patients with cervical spondylotic myelopathy. Acad J Sec Mil Univ 24: 788-790, 2003 